\title{
Validation of Models for the Calculation of Sun Positions and mapped Radiation on inclined Surfaces
}

\author{
Stephan Hirth ${ }^{1, *}$, Dirk Weiß ${ }^{1}$, Andreas Nicolai ${ }^{1}$ and John Grunewald ${ }^{1}$ \\ ${ }^{1}$ TU Dresden, Faculty Of Architecture, Institute For Building Climatology, Germany
}

\begin{abstract}
In order to validate building simulation programs and to identify sources of errors in implemented models, it is necessary to evaluate individual physical effects step by step. For building simulations, the radiation load that hits buildings is a significant boundary condition. In order to reproduce these loads as accurately as possible, sun position models and weather data adapted to them are necessary. With the help of sun position models, the radiation data (usually available in horizontal or normal radiation) are mapped onto inclined and oriented surfaces. This paper examines a possible validation. For the analysis, different building simulation tools (NANDRAD, Radiance, IDA ICE, Modelica, TRNSYS, ETU Simulation) are compared with different time steps for specific dates using the result data azimuth and altitude. The locations are distributed over the northern and southern hemispheres, inside and outside the tropics and polar circles, and with large deviations from the standard meridian, thus allowing errors to be found in the implemented sun position models. In the following step, these building simulation platforms are compared with regard to their minutely radiation loads on building façades. Errors in the radiation mapping on inclined surfaces are hereby determined.
\end{abstract}

\section{Introduction to Solar Loads}

\subsection{Room Energy Balance}

Fig. 1 shows the boundary conditions for the energy balance equation for indoor air nodes in thermal building simulations.

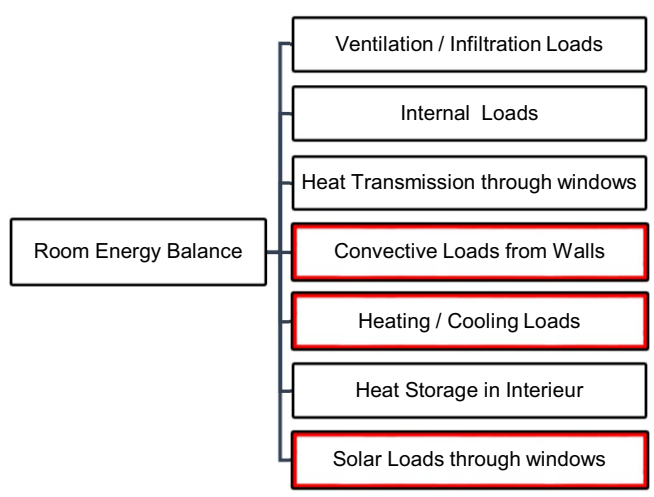

Fig. 1. Room Energy Balance Variables dependening on solar radiation loads highlighted red

The red highlighted boxes in the figure contain variables of the balance equation that are directly or indirectly dependent on solar radiation loads. For thermal building simulations the solar radiation loads have a big impact on heating and cooling demand or thermal behaviour of the building.
This makes it clear that the correct calculation and mapping of these loads on a surface is important and that a detailed investigation is necessary. A possible validation approach for solar radiation loads is described and documented in detail in this paper. This approach has already been carried out within the SIMQUALITY[1] research project and the data presented here are derived from it. Subsequently, the solar radiation loads are described in more detail. After that the validation procedure is shown including the result data for different simulation programs. Finally, possible problems and questions are explained.

\subsection{Definition of the Sun Position}

To calculate a solar radiation load on a surface the exact sun position for each time step must be calculated. To describe the position of the sun several different systems exist. In this paper, the horizontal coordinate system is used to describe the position of the sun with azimuth and altitude as shown in Fig. 4.

The azimuth gives the direction of the sun with the fixed point at North and a positive count towards east. The Altitude describes the elevation angle of the sun above the horizon with positive sign. To determine the exact sun position the latitude lat, the longitude lon and the time zone $t z$ of the location are to be calculated.

\footnotetext{
* Corresponding author: stephan.hirth@,tu-dresden.de
} 


\subsection{Calculation of the sun position}

The following equations show a possible model for the calculation of the sun position for each time step of a year [2][3]. The sun position model described below is implemented in the CCM-Library[4]. It is used in NANDRAD[5] to calculate the sun position.

Standard longitude lon $_{\text {Standard }}$ :

$$
\operatorname{lon}_{\text {Standard }}=\mathrm{tz} \cdot 15^{\circ}
$$

Longitude deviation to standard meridian correction $\Delta \mathrm{t}_{\text {long }}$ :

$$
\begin{gathered}
\Delta \text { lon }=\operatorname{lon}_{\text {Standard }}-\operatorname{lon}_{\text {local }} \\
\Delta \mathrm{t}_{\text {long }}=-\Delta \operatorname{lon} \frac{4 \mathrm{~min}}{\operatorname{deg}}
\end{gathered}
$$

Corrected time with longitude, $\mathrm{t}_{\mathrm{d}}$ apparent solar time:

$$
\mathrm{t}_{\mathrm{d} \text {,lon }}=\mathrm{t}_{\mathrm{d}}+\Delta \mathrm{t}_{\text {long }}
$$

Correction of day length due to eccentricity and earth's orbit around sun $\Delta \mathrm{t}_{\mathrm{exc}}$ :

$$
\begin{gathered}
B=2 \pi \frac{t_{d, l o n}-81}{365} \\
\Delta t_{\text {exc }}=9.87 \sin (2 B)-7.53 \cos (B)- \\
15 \sin (B)[\min ]
\end{gathered}
$$

Equation of time ET:

$$
\mathrm{ET}=\mathrm{t}_{\mathrm{d}}+\Delta \mathrm{t}_{\text {lon }}+\Delta \mathrm{t}_{\mathrm{exc}}
$$

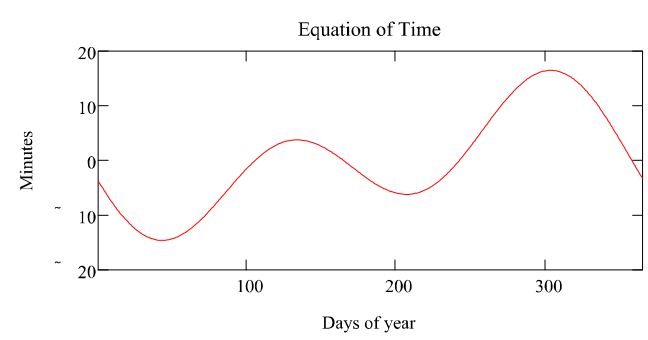

Fig. 2. Equation of Time

Declination angle $\delta$ :

$$
\delta=23.45 \sin \left(2 \pi \frac{\mathrm{ET}+284}{365}\right)
$$

Hour angle $h$ :

$$
\mathrm{h}=2 \pi(\mathrm{ET}-\lfloor\mathrm{ET}\rfloor-0.5)
$$

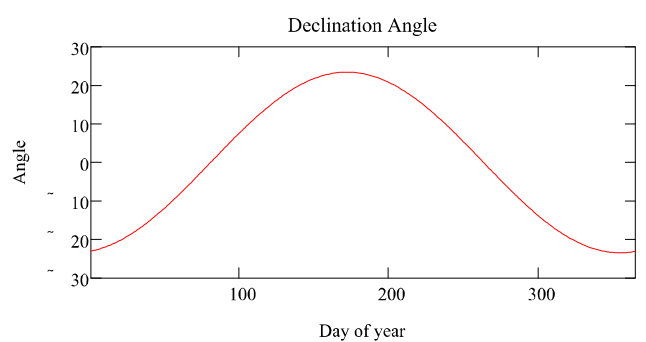

Fig. 3. Declination Angle
Altitude of sun $\gamma_{s}$ :

$$
\begin{gathered}
\sin \left(\gamma_{s}\right)=\sin (\text { lat }) \cdot \sin (\delta)+\cdots \\
\cos (\text { lat }) \cdot \cos (\delta) \cdot \cos (h)
\end{gathered}
$$

Azimuth of $\operatorname{sun} \alpha_{s}$ :

$$
\tan \left(\alpha_{s}\right)=\frac{-\sin (h)}{\tan (\delta) \cdot \cos (\text { lat })-\sin (\text { lat }) \cdot \cos (h)}
$$

\subsection{Calculation of Solar Radiation Loads on inclined surfaces}

To calculate the exact solar radiation on an inclined surface the position of the sun at each time step has to be known. Subsequently the solar radiation loads from the climate file mapped onto the surface are calculated.

The following equations show a possible model to calculate the radiation load for any randomly inclined and rotated surface. There is only an isotropic model for calculating the diffuse radiation noted. The documented model is implemented in the CCM-Library and thus in NANDRAD.

$\begin{array}{cl}\alpha_{s} & \text { Azimuth of sun } \\ \gamma_{s} & \text { Altitude (elevation angle) of sun } \\ \alpha_{p} & \text { Azimuth of the inclined surface } \\ \beta_{p} & \text { Tilt angle / inclination angle of the surface } \\ \theta & \text { Declination angle }\end{array}$

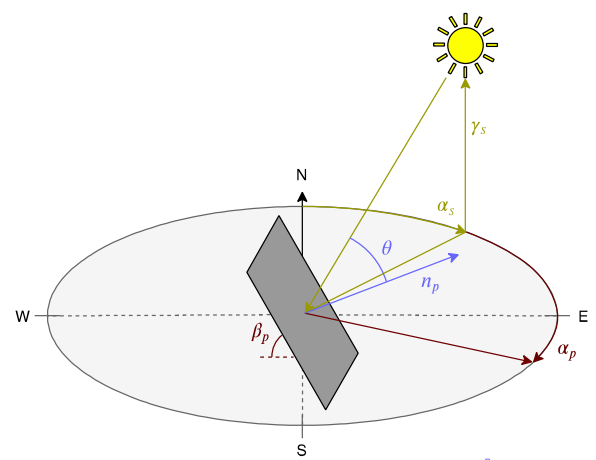

Fig. 4. Definition of the different angles for the sun position

Global radiation on an inclined surface:

$$
Q_{\text {rad,sur }}=Q_{\text {rad,dir,sur }}+Q_{\text {rad,diff,sur }}
$$

Incidence angle:

$$
\begin{gathered}
\cos (\theta)=\cos \left(\beta_{\mathrm{p}}\right) \cdot \sin \left(\gamma_{\mathrm{s}}\right)+\sin \left(\beta_{\mathrm{p}}\right) \cdot \cos \left(\gamma_{\mathrm{s}}-\alpha_{\mathrm{p}}\right) \\
\cdot \cos \left(\gamma_{\mathrm{s}}\right)
\end{gathered}
$$

Direct Radiation:

$$
\begin{gathered}
\mathrm{Q}_{\text {rad,dir,nor }}=\frac{\mathrm{Q}_{\text {rad,dir,hor }}}{\sin \left(\gamma_{\mathrm{s}}\right)} \\
\mathrm{Q}_{\text {rad,dir,surf }}=\cos (\theta) \cdot \mathrm{Q}_{\mathrm{rad}, \text { dir,nor }}
\end{gathered}
$$

Diffuse Radiation (isotropic model) includes the ground reflectance:

$$
\begin{aligned}
Q_{\text {rad,diff,sur }}=\cos ^{2}\left(0.5 \beta_{p}\right) \cdot Q_{\text {rad,diff,hor }}+\alpha_{\text {ground }} \\
\cdot \sin \left(0.5 \beta_{p}\right) \cdot\left(Q_{\text {dir,hor }}+Q_{\text {diff,hor }}\right)
\end{aligned}
$$




\section{Validation of Solar Radiation Loads}

In this section, a possible validation approach for correct solar radiation loads will be proposed. This means that first the sun position model and afterwards the solar radiation mapping on an inclined surface will be validated. For each validation test, a program will be set as the reference in order to carry out cross-platform checks. For each validation however it still needs to be discussed which program or data should be set as reference. It will only show a certain methodology for a possible validation approach.

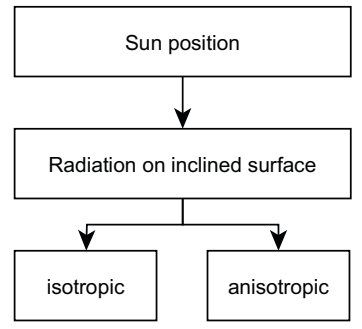

Fig. 5. Validation overview for solar radiation loads

\subsection{Validation of sun position models}

In the first step, the sun position model of each will be validated. The test case for the validation is described in detail below.

\subsubsection{Participating programs}

Table 1. programs participating in the validation task

\begin{tabular}{|c|c|}
\hline program & Version \\
\hline NANDRAD[5] & 1.4 \\
\hline Radiance & 5.2 .0 \\
\hline IDA ICE & 4.8 .0 .1 \\
\hline TRNSYS & 18 \\
\hline ETU Simulation & 4.1 \\
\hline ETU HottCAD & $5.1 . x .19$ \\
\hline Modelica & $\begin{array}{c}\text { Dymola Ver 4.1 } \\
\text { AixLib 0.7.3[9] }\end{array}$ \\
\hline TAS & 9.3 \\
\hline
\end{tabular}

All programs shown in Table 1 take part in this validation task. Since some programs show deviations in the validation task and are currently working on improving the results only anonymised results are shown.

\subsubsection{Locations}

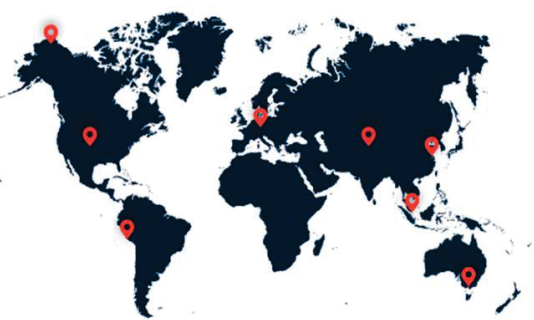

Fig. 4. Illustration of the different locations for the sun position validation
In order to test and validate different sun position models profoundly several locations are tested. The locations for the investigation of the solar altitude models are distributed worldwide and each has certain characteristics. This has been procedure has been choosen since some locations can lead to faulty sun positions. Fig. 4 provides an overview of the locations spread in the northern and southern hemisphere and within the tropics and polar circles. Table 1 provides a detailed overview of the locations with a brief description of the individual situation that affects the calculation.

Table 2. Locations for the sun position validation

\begin{tabular}{|c|c|c|c|c|}
\hline Location & $\begin{array}{l}\text { Longitude } \\
\text { in } \circ\end{array}$ & $\begin{array}{l}\text { Latitude } \\
\text { in }{ }^{\circ}\end{array}$ & $\begin{array}{l}\text { Time- } \\
\text { zone }\end{array}$ & Note \\
\hline Barrow & -156.78 & 71.30 & -9 & $\begin{array}{c}\text { Inside the northern } \\
\text { polar circle }\end{array}$ \\
\hline Denver & -104.86 & 39.76 & -7 & $\begin{array}{l}\text { Small distance to } \\
\text { the standard } \\
\text { meridian }\end{array}$ \\
\hline Lima & -77.12 & -12.00 & -5 & $\begin{array}{l}\text { In the southern } \\
\text { hemisphere and } \\
\text { within the } \\
\text { southern solstice } \\
\text { circle }\end{array}$ \\
\hline Potsdam & 13.067 & 52.383 & 1 & $\begin{array}{l}\text { Small distance to } \\
\text { the standard } \\
\text { meridian on the } \\
\text { east side }\end{array}$ \\
\hline Shanghai & 121.43 & 31.17 & 8 & $\begin{array}{c}\text { Short distance } \\
\text { from the standard } \\
\text { meridian }\end{array}$ \\
\hline Kaxgar & 75.98 & 39.47 & 8 & $\begin{array}{c}\text { Very large } \\
\text { distance to the } \\
\text { standard meridian } \\
\text { (same time zone } \\
\text { as Shanghai) }\end{array}$ \\
\hline Singapore & 103.98 & 1.37 & 8 & $\begin{array}{l}\text { Small distance to } \\
\text { the equator and } \\
\text { within the } \\
\text { northern solstice } \\
\text { circle }\end{array}$ \\
\hline Melbourne & 144.83 & -37.67 & 10 & $\begin{array}{l}\text { In the southern } \\
\text { hemisphere } \\
\text { outside the solar } \\
\text { tropic }\end{array}$ \\
\hline
\end{tabular}

\subsubsection{Dates}

To get a broad insight into the sun positions yearly output with an hourly step size and 5 different days with minutely output will be investigated. These dates are chosen by the ASHRAE 140 BESTest[11] and have been extended to cover the whole year.

The calculation results are compared for the following days with minutely output:

- 5. March

- 27. July

- 22. September

- 24. October

- 17. December 


\subsubsection{Results}

Fig. 6 shows the azimuth and altitude for the $22^{\text {nd }}$ of September for the location of Barrow and Fig. 7 shows the azimuth and altitude for the $24^{\text {th }}$ of October for the location of Lima. Fig. 6 shows that the individual models certainly lead to different solar elevations. This also happens for locations such as Lima where the sun is close to the zenith shown in Fig. 7. For program 6 and 9 only the sun position angles are given when the sun is over the horizon $\left(\gamma_{s}>0^{\circ}\right)$
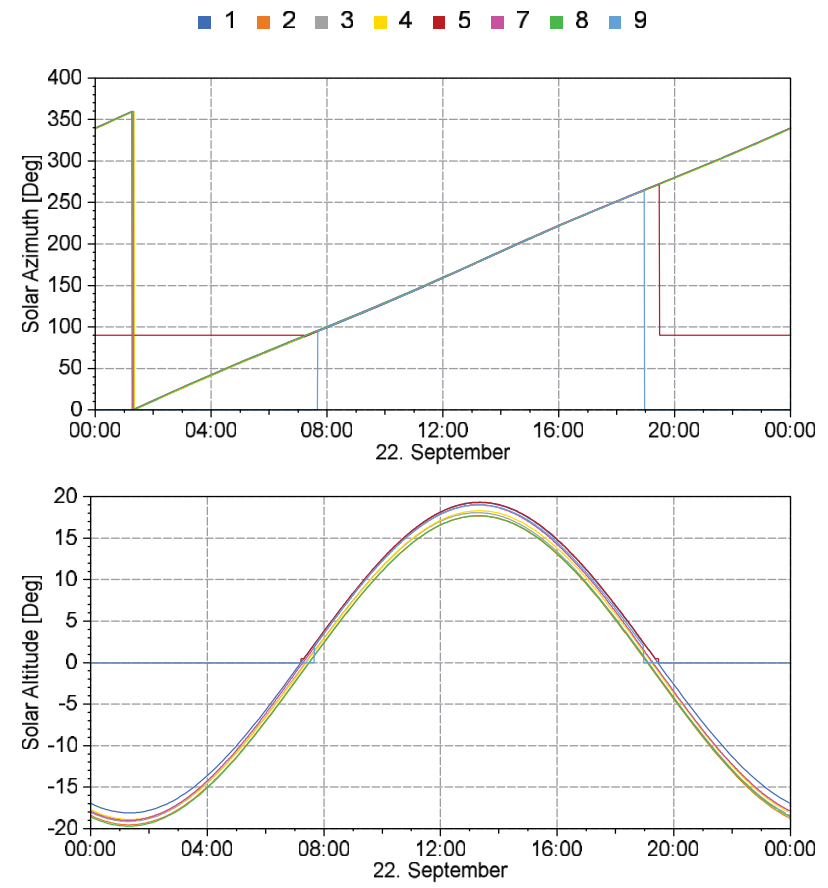

Fig. 6. Azimuth and Altitude for 22nd of September for Barrow
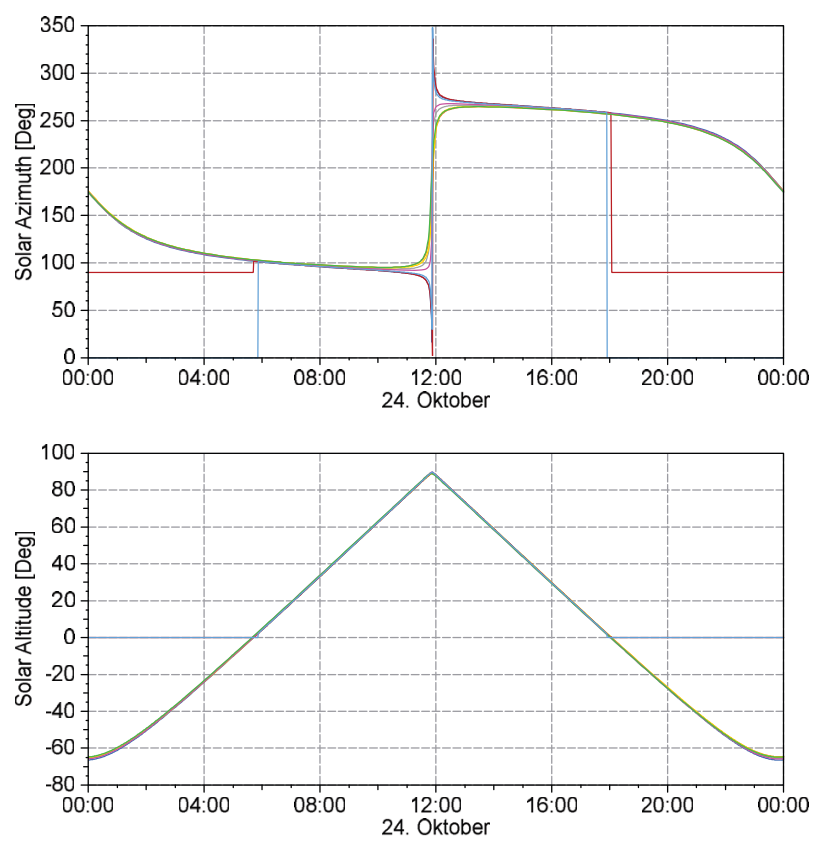

Fig. 7. Azimuth and Altitude for 24th of October for Lima

\subsubsection{Evaluation}

A cross checking of the altitude and azimuth is not working for altitude angles that get closer to the zenith $\left(\gamma_{s}=90^{\circ}\right)$ as the position of the sun at the sky is the same whereas the azimuth angle can diver strongly.

To find a better criteria to cross check the sun position, the vector of the sun ray in the Cartesian coordinate system will be determined for each calculated time step (minute, hour) from the specified azimuth and altitude. Subsequently the determined vector is compared with the vector of the reference program at the same time step. For this purpose, the angle spanned by both vectors is determined via the scalar product and considered to be deviating from a value of more than 3 degrees. The reference values for the comparison are taken from program 4. For the respective whole day and for the hours in which the sun is above the horizon (sunshine hours) the sum of all minutes with deviation over the comparison period is determined.

Table 3 Number of minutes with deviation between the reference program (program 4 ) and the evaluated programs. (only programs with deviation shown)

\begin{tabular}{|c|c|c|c|}
\hline Location & Date & Program 2 & Program 5 \\
\hline Barrow & Ju127 & 1 & 86 \\
\hline Denver & Dec17 & & 1 \\
\hline Kaxgar & Dec17 & & 1 \\
\hline \multirow{5}{*}{ Lima } & Mar5 & 1 & 1 \\
\cline { 2 - 4 } & Ju127 & 1 & \\
\cline { 2 - 4 } & Sep22 & 1 & \\
\cline { 2 - 4 } & Oct24 & & 1 \\
\cline { 2 - 4 } & Dec17 & & 2 \\
\hline \multirow{5}{*}{ Melbourne } & Mar5 & 1 & 2 \\
\cline { 2 - 4 } & Jul27 & 1 & 3 \\
\cline { 2 - 4 } & Sep22 & 1 & 9 \\
\cline { 2 - 4 } & Oct24 & 1 & 1 \\
\cline { 2 - 4 } & Dec17 & 1 & 1 \\
\hline Shanghai & Dec17 & & \\
\hline \multirow{5}{*}{ Singapur } & Ju127 & 1 & \\
\cline { 2 - 4 } & Dec17 & & \\
\hline & & & \\
\hline
\end{tabular}

Table 3 shows the sum of all deviations between program 4 and the regarded program for all tested dates and locations. Only program 2 and program 5 are shown since the other tested programs had no deviation to program 4. In Table 4 the validation of program 2 is shown. Table 3 indicates that program 2 has often only one minute at some days that deviates from the reference program which is considered as a cosmetic problem. Program 5 shows at the location Barrow around midnight a faulty altitude angle ( 0 degree) when the sun is still up. Therefore it is not validated for Barrow. All other locations with small 
deviations are considered to be cosmetic and are therefore validated.

Table 4. Validation result of program 2 (program 4 as Reference) for the sun positions

\begin{tabular}{|c|c|c|c|c|c|c|c|c|}
\hline Date & $\begin{array}{l}\text { हे } \\
\text { हू } \\
\text { صू }\end{array}$ & $\begin{array}{l}\bar{\Delta} \\
\vec{D} \\
\end{array}$ & 思 & 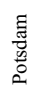 & 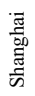 & 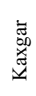 & 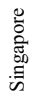 & 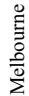 \\
\hline Mar5 & a & a & च & 口 & a & 口 & a & च \\
\hline Jul27 & 口 & $\mathbf{\square}$ & 口 & $\mathbf{\square}$ & $\square$ & $\mathbf{\square}$ & $\mathbf{\square}$ & - \\
\hline Sep22 & 口 & 口 & 口 & 口 & - & 口 & - & $\square$ \\
\hline Oct24 & 口 & 口 & 口 & 口 & 口 & 口 & 口 & 口 \\
\hline Dec17 & 口 & $\mathbf{\square}$ & 口 & 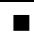 & - & 口 & - & - \\
\hline Validation & 口 & 口 & 口 & $\square$ & 口 & $\square$ & 口 & च \\
\hline
\end{tabular}

\subsection{Validation of solar radiation on inclined surfaces}

In the second step of the here described validation approach, the mapped radiation on an inclined surface will be validated. In order to take part in this validation it is necessary to pass the validation of the sun position model. This validation approach is described in detail below.

\subsection{1 programs}

Since not every program took part in the sun's position validation, only the programs shown in Table 5 are investigated in this research. Some programs show deviations in the validation task and are currently working on improving the results of the validation task and therefore only anonymised results are shown.

Table 5. Programs that took part in the validation task

\begin{tabular}{|c|c|}
\hline Program & Diffuse Radiation Model \\
\hline NANDRAD & Isotrop \\
\hline IDA ICE & Anisotrop (Perez) \\
\hline TRNSYS (1) & Isotrop \\
\hline TRNSYS (2) & Anisotrop (Perez) \\
\hline ETU Simulation & Anisotrop \\
\hline Modelica AixLib & Isotrop \\
\hline
\end{tabular}

As program 6 is highly developed concerning the solar radiation models it will be chosen as the reference for this test case.

\subsubsection{Model}

In order to validate the different models that map the radiation a surface with an area of $1 \mathrm{~m}^{2}$ having different inclinations and orientations are defined. Table 6 shows an overview of the different surfaces that must be modelled in this test case.

To validate radiation loads on differently inclined and orientated directions this paper will only focus on two surfaces - an east oriented surface with $90^{\circ}$ inclination
(E90) and a west oriented surface with $30^{\circ}$ inclination (W30).

Table 6. Overview of tested surfaces with given inclination and orientation

\begin{tabular}{|c|c|c|c|c|c|}
\hline \multicolumn{2}{|c|}{ Orientation } & \multicolumn{4}{|c|}{ Inclination $\boldsymbol{\beta}_{\boldsymbol{p}}$} \\
\hline $\begin{array}{c}\text { Direction of } \\
\text { normal }\end{array}$ & Angle $\alpha_{p}$ & $90^{\circ}$ & $60^{\circ}$ & $45^{\circ}$ & $30^{\circ}$ \\
\hline $\mathrm{N}$ & 0 & $\mathbf{\square}$ & $\square$ & $\square$ & $\mathbf{\square}$ \\
\hline $\mathrm{N}-\mathrm{E}$ & 45 & $\mathbf{\square}$ & $\square$ & $\square$ & $\mathbf{\square}$ \\
\hline $\mathrm{E}$ & 90 & $\mathbf{\square}$ & $\square$ & $\square$ & $\mathbf{\square}$ \\
\hline $\mathrm{S}-\mathrm{E}$ & 135 & $\mathbf{\square}$ & $\square$ & $\square$ & $\mathbf{\square}$ \\
\hline $\mathrm{S}$ & 180 & $\mathbf{\square}$ & $\square$ & $\square$ & $\mathbf{\square}$ \\
\hline $\mathrm{S}-\mathrm{W}$ & 225 & $\mathbf{\square}$ & $\square$ & $\square$ & $\mathbf{\square}$ \\
\hline $\mathrm{W}$ & 270 & $\mathbf{\square}$ & $\square$ & $\square$ & $\mathbf{\square}$ \\
\hline $\mathrm{N}-\mathrm{W}$ & 315 & $\mathbf{\square}$ & $\square$ & $\square$ & $\mathbf{\square}$ \\
\hline
\end{tabular}

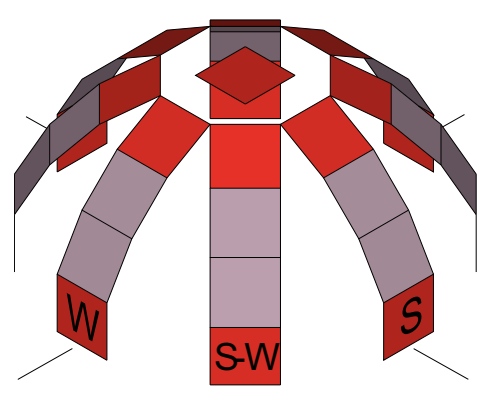

Fig. 8. Example model for the tested surfaces. Red surfaces are mandatory grey surfaces are optional

\subsubsection{Locations}

Concerning the location Potsdam was chosen for this test case. Since the validation of the sun position already showed possible inaccuracies or model errors at different locations there is no need to test several locations. The test reference year of 2010 TRY2010 of Potsdam in the epwformat is taken.

\subsubsection{Dates}

For the validation the same dates as used in the validation of the sun position will be taken.

\subsubsection{Results}

In Fig. 9 diffuse, direct and global Solar Radiation is shown for the surface oriented West with an inclination of $30^{\circ}$ on the $27^{\text {th }}$ of July and in Fig. 9 diffuse, direct and global Solar Radiation is shown for the surface oriented East with an inclination of $90^{\circ}$ on the $22^{\text {nd }}$ of September.

To get a better overview, the daily energy integral is moreover shown. It becomes obvious that all programs calculate very different curves for the solar radiation over the day and the deviations are therefore significant. Program 1 has very jagged radiation loads over the day program 4 has a constant offset to the back. Program 6 usually shows the highest maxima during the day. Program 2 always lies in between. The possible effects are discussed hereafter in the evaluation section. 
$1 \square 2 \square 3 \square 4 \square 5 \square 6$

DIR_W_30_Jul27
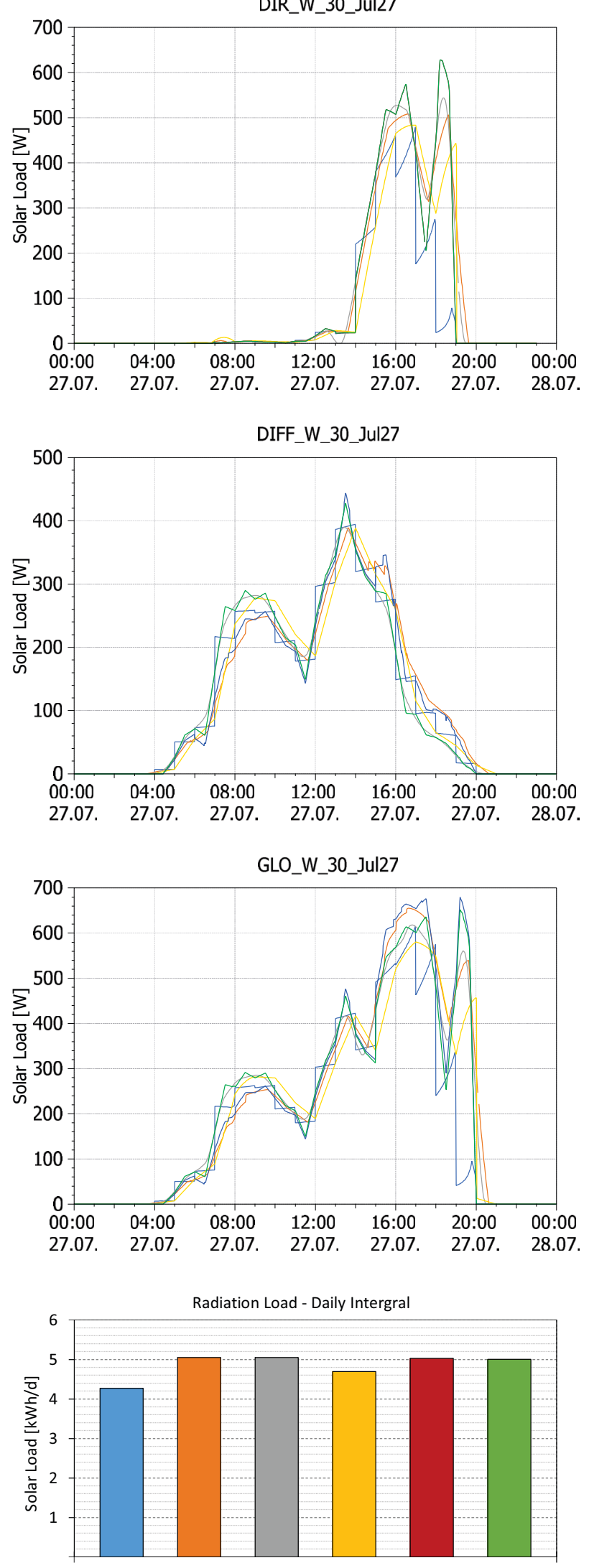

Jul27 W30

Fig. 9. Radiation Loads on the surface oriented West with an inclination of $30^{\circ}$ for $27^{\text {th }}$ of July (W30) \begin{tabular}{r|l|l|l|l|l}
1 & 2 & 3 & 4
\end{tabular}
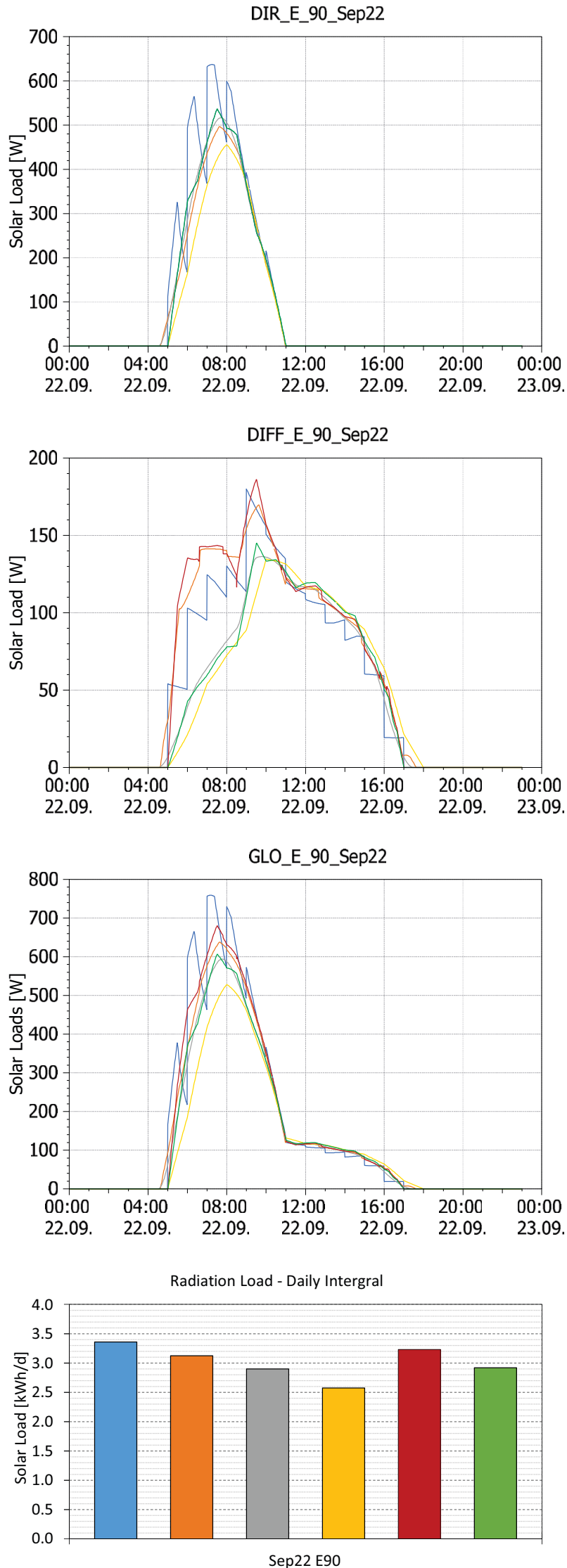

Fig. 10. Radiation Loads on the surface oriented East with an inclination of $90^{\circ}$ for $22^{\text {nd }}$ of September (E90) 


\subsubsection{Evaluation}
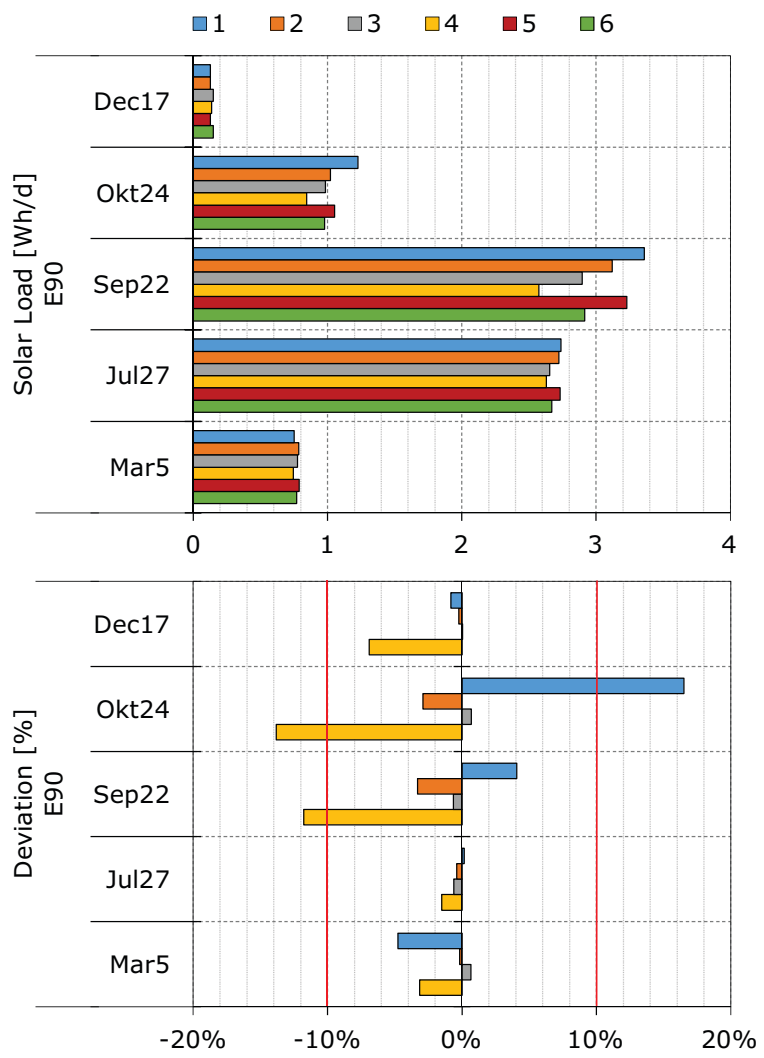

Fig. 11. Radiation Loads Evaluation (direct, diffuse and global) for the surface oriented East with an inclination of $90^{\circ}$
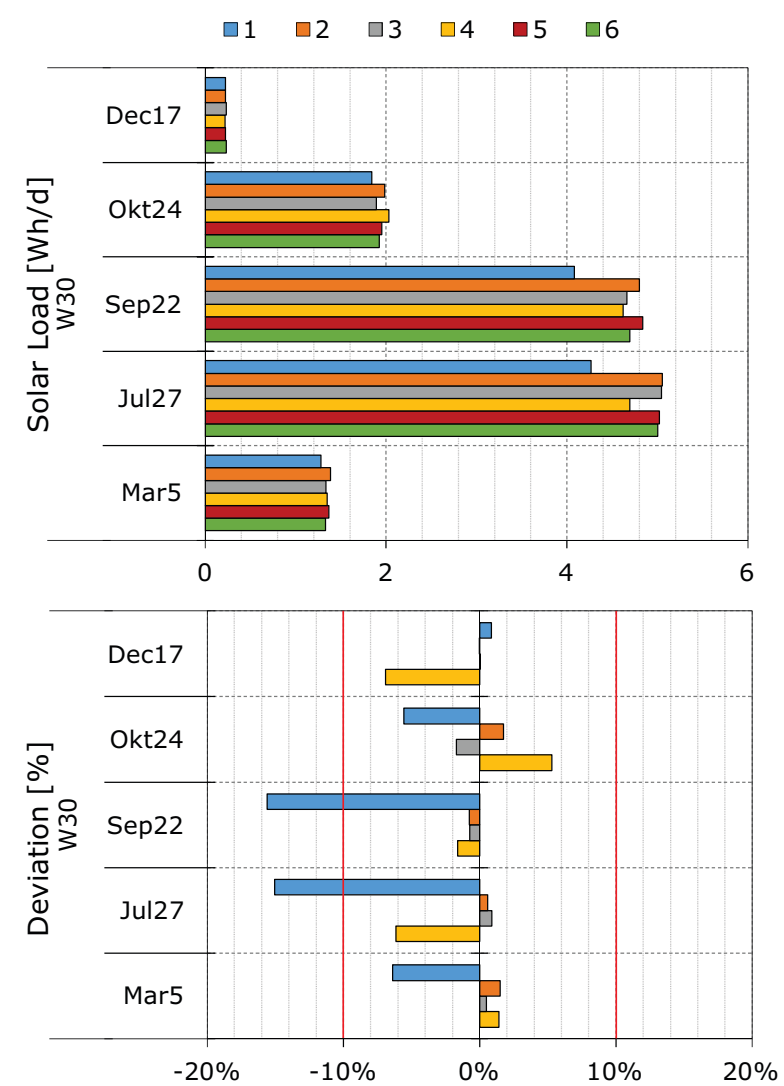

Fig. 12. Radiation Loads Evaluation (direct, diffuse and global) for the surface oriented East with an inclination of $90^{\circ}$
Table 7. Validation overview for the solar radiation daily energy integral on surface E90 and W30 for program 4

\begin{tabular}{|c|c|c|}
\hline Program 4 & E90 & W30 \\
\hline Mar5 & $\mathbf{\square}$ & $\mathbf{\square}$ \\
\hline Jul27 & $\mathbf{\square}$ & 口 \\
\hline Sep22 & $\square$ & 口 \\
\hline Okt24 & $\square$ & 口 \\
\hline Dez17 & 口 & 口 \\
\hline Validation & $\square$ & च \\
\hline
\end{tabular}

For surface E90 the evaluation results are shown in Fig. 11 and for surface W30 the evaluation results are shown in Fig. 12.

In this test case, the evaluation for all programs with isotropic or anisotropic radiation model as shown in Table 8 are split up. As mentioned before program 6 serves as the reference program for isotropic radiation model types and program 5 as the reference for anisotropic radiation model types.

Table 8. Reference programs for the validation tasks

\begin{tabular}{|c|c|c|}
\hline Model & Reference & programs \\
\hline Anisotropic & program 5 & program 1, program 2 \\
\hline Isotropic & program 6 & program 3, program 4 \\
\hline
\end{tabular}

The deviation of each program is based on the reference program. To validate the solar radiation load on the surfaces the solar radiation energy integral for all dates will be calculated and the deviation should not be over $10 \%$ from the reference. It is to be questioned how the qualitative course of the radiation loads is to be evaluated. As Fig. 9 and Fig. 10 show, the difference between the individual programs is significant. This question needs to be discussed further.

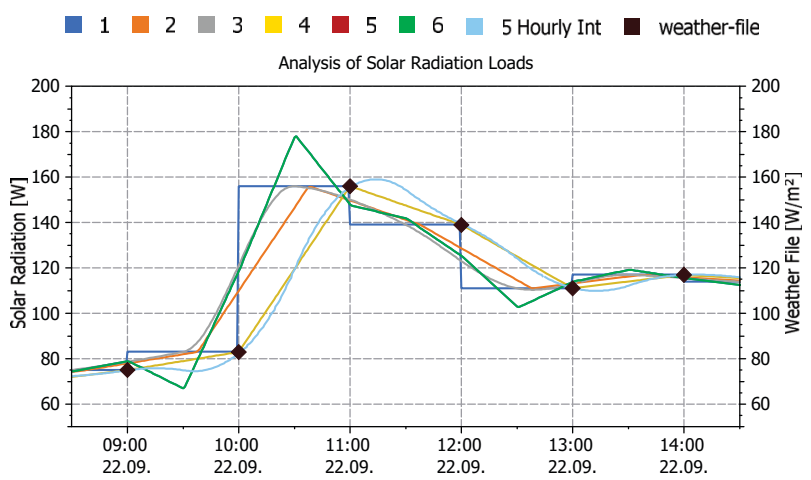

Fig. 13. Comparison of all programs regarding the distribution of the radiation values from the climate file. Diffuse radiation on a horizontal surface is shown

These deviations can have several reasons. One particular cause is the interpretation of the solar radiation data from the climate file as shown in Fig. 13. In this the course of the diffuse solar radiation on a horizontal surface is shown so that the mapping of the radiation data to the sun position does not affect the comparison. Program 6 interprets the radiation values from the climate file as an hourly integral and then calculates the course over the 
day, so that the hourly integral at the end of each hour step fits to the solar radiation value from the climate file. Program 1 interprets the radiation data as constant values for each hour and therefore the curves are jagged. Program 4 interprets the radiation values from the climate file as momentary values and therefore it is shifted to the back and its integrals are usually too small since the sun position does not fit to the radiation value from the climate file. Program 3 calculates a strongly attenuated radiation pattern throughout the day and the maximum hourly integral values are not reached either. The situation is similar for program 2. It calculates the radiation intensities based on the radiation values from the climate file and shifts the course by about half an hour to the front. However, this means that the hour integrals also deviate and do not fit to the climate file.

\subsection{Validation results}

Table 9 shows an overview of the complete validation approach for the solar radiation loads. It shows that program 2, 3, 5 and 6 are the only thermal simulation programs that are able to pass the validation approach. Program 1 and 4 have either difficulties with the sun positioning or the mapping of radiation loads on an inclined surface.

Table 9. Validation overview for all programs

\begin{tabular}{|c|c|c|c|c|c|c|}
\hline & Program 1 & Program 2 & Program 3 & Program 4 & Program 5 & Program 6 \\
\hline Sun position model & - & 口 & - & ref & घ & $\mathbf{\square}$ \\
\hline $\begin{array}{l}\text { Solar Radiation on } \\
\text { inclined surfaces }\end{array}$ & $\square$ & च & च & $\square$ & ref & ref \\
\hline Validation & $\square$ & 口 & $\mathbf{\square}$ & $\square$ & $\mathbf{\square}$ & 口 \\
\hline
\end{tabular}

\section{Conclusion}

In this paper, a possible cross-program validation approach was explained and carried out to compare solar radiation loads for thermal building simulation programs.

First the position of the sun and after that the radiation on an inclined surface were calculated. In order to test the sun position model profoundly, several worldwide spread locations and dates distributed over the year were calculated and compared with output data in minute steps. Furthermore, the solar radiation on several inclined planes was compared for the location of Potsdam. In order to provide a wide range of different simulation programs, various tools that modelled the test cases within the research project SIMQUALITY[1] were compared.

It was shown that the calculated sun positions of the individual programs are very close together. Moreover, the solar loads on the inclined surfaces were compared. The results show that there are big differences between all programs concerning the interpretation and mapping of solar radiation loads from the climate file onto an inclined surface.
That demonstrates the importance of a stepwise validation of every single physical effect in thermal building simulation programs. The more complex models become and the more parameters influence them, the more difficult it becomes to detect possible model or implementation errors. Hence, there is a need for wellelaborated and accurate validation procedures for single physical effects to get correctly working programs. In this paper a procedure for the validation of solar radiation loads has been developed and described.

\section{References}

1. German National Research Project: SimQuality Development of quality standards for energetic building and district simulation as a planning tool Funding reference number 03ET1570B

2. L. Soteris, Solar energy engineering: processes and systems (USA, 2009)

3. USNO, Computing Altitude and Azimuth from Greenwich Apparent Sidereal Time (2017)

4. CCM Library - Library to calculate climate boundary data for thermal simulations from the Institute for builing climatology, Dresden - can be found under: https://bauklimatik-dresden.de/

5. program 4 - building energy simulation tool from the Institute for builing climatology, Dresden - can be found under: https://bauklimatik-dresden.de/nandrad/ index.php

6. J.A Duffie, W.A Beckman, Solar energy thermal processes (1974)

7. T. Markus, Solar Position Calculation - Comparison of Different Calculations of the Position of the Sun as a Function of Position and Time (Germany, 2009)

8. S.Maleki, H. Hizam, C. Gomes, Review Estimation of Hourly, Daily and Monthly Global Solar Radiation on Inclined Surfaces: Models Re-Visited, (2017)

9. AixLib - program 3 model library for creating building and system simulations from the E.ON Energy Research Center, Chair for Building and Indoor Climate Technology at RWTH Aachen University. -can be found under: http://ibpsagermany.org/ wordpress/tools

\section{EnergyPlus Weather-file}

11. ASHRAE 140-2017, Standard Method of Test for the Evaluation of Building Energy Analysis Computer programs 